\title{
Erratum to: A Colorimetric and Fluorescent Probe Based on Michael Acceptor Type Diketopyrrolopyrrole for Cyanide Detection
}

\author{
Lingyun Wang ${ }^{1} \cdot$ Shaochun Zhuo ${ }^{1} \cdot$ Derong Cao ${ }^{1}$
}

Published online: 13 June 2017

(C) Springer Science+Business Media New York 2017

Erratum to: J Fluoresc

DOI 10.1007/s10895-017-2079-1

The original article was corrected. The spelling of the second author name was corrected to "Shaochun Zhuo".

The online version of the original article can be found at http://dx.doi.org/ 10.1007/s10895-017-2079-1

Lingyun Wang

lingyun@scut.edu.cn

1 Key Laboratory of FunctionalMolecular Engineering of Guangdong Province, School of Chemistry and Chemical Engineering, South China University of Technology, Guangzhou 510641, China 